\title{
Derivation of combined species sensitivity distributions for acute toxicity of pyrethroids to aquatic animals
}

\author{
Jeffrey M. Giddings $\mathbb{( i b}^{1} \cdot$ Jeffrey Wirtz ${ }^{1}$ - David Campana ${ }^{1} \cdot$ Michael Dobbs $^{2}$
}

Accepted: 16 January 2019 / Published online: 13 February 2019

(C) The Author(s) 2019

\begin{abstract}
The aquatic toxicity profiles of synthetic pyrethroid insecticides are remarkably similar, and results for a large number of species can be combined across compounds in Species Sensitivity Distributions (SSDs). Normalizing acute toxicity values (median lethal concentrations, LC50s) for each species and each pyrethroid to the LC50 of the same pyrethroid to the freshwater amphipod Hyalella azteca (the most sensitive species to all pyrethroids tested) enabled expression of LC50s as Hyalella equivalents that can be pooled across pyrethroids. The resulting normalized LC50s (geometric means for each species across pyrethroids) were analyzed using SSDs. Based on tests with measured exposure concentrations, the fifth percentiles (Hazard Concentrations, HC5s) of the SSDs were 4.8 Hyalella equivalents for arthropods (36 species) and 256 Hyalella equivalents for fish (24 species). HC5 values are useful as effects metrics for screening-level risk assessments, and the full SSDs can be integrated with estimated exposure distributions for higher-level risk characterization. The combined pyrethroid SSDs provide a more taxonomically representative and statistically robust basis for risk characterization than data for the most sensitive single species or SSDs based on data for a single pyrethroid alone, and are especially useful for pyrethroids that have been tested with smaller numbers of species.
\end{abstract}

Keywords Pyrethroids $\cdot$ Aquatic toxicity $\cdot$ Species sensitivity distribution $\cdot$ Crustaceans $\cdot$ Insects $\cdot$ Fish

\section{Introduction}

Synthetic pyrethroids are a class of insecticides registered for agricultural, residential, and public health uses for more than 35 years. These compounds are synthetic analogs of pyrethrins, which are naturally occurring esters found in the flower of the pyrethrum plant, Tanacetum cinerariifolium. Pyrethroids are highly toxic to insects and some other arthropod groups but have relatively low toxicity to vertebrates. Commonly used pyrethroid active ingredients (AIs) include bifenthrin, cyfluthrin, cypermethrin, deltamethrin,

Supplementary information The online version of this article (https:// doi.org/10.1007/s10646-019-02018-0) contains supplementary material, which is available to authorized users.

Jeffrey M. Giddings

jgiddings@complianceservices.com

1 Compliance Services International, 7501 Bridgeport Way West, Lakewood, WA 98499, USA

2 Bayer CropScience, 2 TW Alexander Drive, Research Triangle Park, NC 27709, USA esfenvalerate, fenpropathrin, cyhalothrins, and permethrin, among others, as well as various refined isomer mixtures of these compounds. (See SI-1 for Chemical Abstract Service (CAS) numbers.)

Because pyrethroids may enter surface waters through spray drift and surface runoff following insecticide application, their toxicity to aquatic species has been extensively tested. The Pyrethroid Working Group (PWG), a consortium of pyrethroid registrants, has worked for more than a decade to obtain, evaluate, and compile relevant, reliable data on the toxicity of synthetic pyrethroids to aquatic organisms. The PWG aquatic toxicity database (available for public download at www.pyrethroids.com/aquatictoxicity-database/) contains endpoints and supporting information from more than 1100 open literature publications and registrant-sponsored study reports. The database currently includes more than 5300 records for nine pyrethroids (and their isomer variants and degradates) and nearly 350 species (79 crustaceans, 99 insects, 86 fish, 31 mollusks, and 52 other species).

Examination of the extensive aquatic toxicity database for pyrethroids reveals remarkable similarities in the toxicity profiles of different pyrethroid AIs. As shown below, 
the relative sensitivity of crustaceans, insects, fish, mollusks, and aquatic plants to pyrethroids is quite consistent across AIs. Species Sensitivity Distributions (SSDs) are a tool to integrate toxicity data for multiple species for a variety of purposes in ecological risk assessment and environmental regulation (Maltby et al. 2005; Posthuma et al. 2002; Van den Brink et al. 2006). The large number of species tested and the consistency of species sensitivities across pyrethroids provides an opportunity to develop exceptionally robust and comprehensive SSDs that combine data across the pyrethroids as a group. Combining the data across AIs broadens the data available for individual pyrethroids and results in a more complete characterization of species sensitivity. It is especially useful for AIs that have been tested with smaller numbers of species.

The PWG has used combined pyrethroid SSDs in risk assessments for arthropods and fish in two ways. First, the fifth percentiles (Hazard Concentration, HC5) of the combined SSDs are used as benchmarks for risk characterization, specifically as the denominators of Risk Quotients (EPA 2004) for acute risk to arthropods and fish. Second, the full SSDs for arthropods and fish are used as surrogates for natural species assemblages and integrated with distributions of model-derived exposure concentrations to generate Joint Probability Curves (JPCs) depicting the magnitude and likelihood of effects on arthropod and fish communities (ECOFRAM 1999). The combined SSDs are also useful for derivation of water quality criteria for pyrethroids and for evaluation of potential toxicity of pyrethroid mixtures in ambient water. The combined pyrethroid SSDs provide a more taxonomically representative and statistically robust basis for risk characterization than data for the most sensitive species or SSDs based on data for a single AI alone.

This paper describes the selection of data for deriving combined pyrethroid SSDs, the steps in the data analysis, and the resulting acute SSDs for arthropods and fish.

\section{Methods}

The approach to developing combined pyrethroid SSDs involved normalizing the acute toxicity values (LC50s) for each species to the LC50 of the freshwater amphipod Hyalella azteca for the same AI, and expressing the result as Hyalella equivalents. The LC50 values for $H$. azteca are an ideal basis for normalizing the toxicity data. The PWG conducted $H$. azteca acute toxicity tests with 9 PWGsupported pyrethroids (bifenthrin, cyfluthrin, lambda- and gamma-cyhalothrin, cypermethrin, deltamethrin, esfenvalerate, fenpropathrin, and permethrin) between 2012 and 2014 to fulfill data requirements for product registration. All of the tests were conducted in the same laboratory following
Good Laboratory Practices using the same test protocol, the same stock of test organisms, and the same dilution water ${ }^{1}$, and all were categorized as Acceptable by the US Environmental Protection Agency (USEPA) Office of Pesticides (EPA 2016). As such, the data for H. azteca provide a highly reliable and consistent basis for comparison among AIs. Moreover, H. azteca has been found to be the most sensitive aquatic species tested with all of the pyrethroids, and therefore plays a key role in pyrethroid risk assessment.

\section{Selection of toxicity data for analysis}

Acute toxicity data were taken from the PWG pyrethroid aquatic toxicity database described in the Introduction. This database was compiled from reports provided by each of the PWG member companies and from public documents (reports and peer-reviewed publications) identified through a comprehensive literature search. Reports and publications (primary sources) were evaluated using a set of objective criteria $^{2}$, and only studies that met the evaluation criteria were used in the analysis.

A single Key Value was selected for each study using a second set of criteria that included measured endpoint (e.g., LC50 or EC50), exposure duration, measured response (mortality), life stage (most sensitive), test conditions (most closely approximating standard test conditions according to USEPA or other regulatory guidelines), and exposure regime (flow-through preferred over static or staticrenewal). If, after application of Key Value selection criteria, multiple values remained (e.g., in studies with repeated trials, or studies using test organisms from different sources), the geometric mean was calculated and used as the Key Value for that study.

From the set of Key Values (one for each study), a Species Final Value (SFV) was selected for each AI and each species. Criteria for selection of SFVs were similar to those used for selection of Key Values. Key Values from studies with measured exposure concentrations were preferred over nominal concentrations for SFVs. In cases where only one Key Value met the criteria for a given test substance, that Key Value was identified as the SFV. When two or more Key Values met the selection criteria equally, the geometric mean of the Key Values was calculated and used as the SFV. A separate SFV was selected for the technical grade active ingredient (TGAI) and for each formulation or formulation type. Differences between TGAI and formulation toxicity were generally minimal, but only

\footnotetext{
1 The PWG database, publicly available at www.pyrethroids.com/a quatic-toxicity-database/, includes bibliographic information for all data, including the H. azteca studies referred to here. See also Table S3-2.

${ }^{2}$ See SI-2 for criteria used for study evaluation, Key Value selection, and Species Final Value selection.
} 
SFVs for TGAI were used in the SSD analysis. A few SFVs were derived from "greater-than" LC50 values and these were used in the analysis without the "greater-than" sign. All SFVs are shown in SI-3.

More than half of the SFVs were endpoints based on nominal exposure concentrations, or concentrations measured only in the stock solutions or only at test initiation. Data from studies with measured exposure concentrations are considered more reliable than data from studies with nominal concentrations and were used in this analysis. However, because including all studies (measured and nominal concentrations) more than doubled the number of species for which data were available, we also conducted a comparative SSD analysis for each taxon using both measured and nominal SFVs.

\section{Calculation of Hyalella equivalents}

For each species and AI, the LC50 (ng/L) was converted to Hyalella equivalents by dividing the LC50 for that species by the 96-h LC50 for $H$. azteca. The number of resulting Hyalella equivalents (see SI-3) for each species ranged from 1 (i.e., data available for only one AI) to 9 (i.e., data available for all 9 AIs). The geometric mean of the 1-9 Hyalella equivalents for each species was used to represent that species in the combined pyrethroid SSD. The final sets of geometric mean Hyalella equivalents were the basis for the combined pyrethroid SSDs.

\section{Statistical analysis}

Each set of geometric mean Hyalella equivalent LC50s (Table 1) was analyzed using the USEPA SSD Generator V1, available at https://www.epa.gov/caddis-vol4/caddisvolume-4-data-analysis-download-software. This tool uses Microsoft Excel $^{\circledast}$ functions to estimate the slope and intercept of a linear regression model with $\log (\mathrm{LC} 50)$ (in this case, expressed as Hyalella equivalents) as the independent variable and normalized species rank as the dependent variable. Species rank is expressed as a percentile (p) using the Hazen relationship: $\mathrm{p}=(\mathrm{n}-0.5) / \mathrm{N}$, where $\mathrm{n}$ is the rank of the species and $\mathrm{N}$ is the total number of species. Hazen values are normalized using the Excel NORMINV() function for use in the regression analysis. The prediction intervals for the concentration corresponding to a given percentile (e.g., the HC5) are estimated using the method of Neter et al. (1990).

\section{Results}

The final sets of mean Hyalella equivalent LC50s are shown in Table 1 (arthropods) and Table 2 (fish). The individual
Hyalella equivalents for each AI are presented in SI-3. Figure 1 shows the distributions of Hyalella equivalent LC50s for crustaceans, insects, and fish, as well as for amphibians and mollusks (which were not included in the SSDs; data shown in SI-3) for tests with measured concentrations. The median Hyalella equivalent LC50 for crustaceans was nearly two orders of magnitude greater than the lowest LC50 (1 Hyalella equivalent for H. azteca). The median for insects was 186 Hyalella equivalents, and the median for fish was 1700 Hyalella equivalents. Data were available for only two amphibian species, both approximately 10,000 Hyalella equivalents. Mollusks ranged from 2200 to 1,000,000 Hyalella equivalents.

Individual SSDs for each taxon with prediction intervals and data points are shown in Fig. 2 (arthropods) and Fig. 3 (fish). The model parameters (lognormal regression intercept and slope) and the estimated HC5 values and prediction intervals are shown in Table 3. The HC5 for 36 arthropod species (Fig. 2) was 4.8 (95\% prediction interval 2.8-8.3) Hyalella equivalents. The HC5 for 24 fish species (Fig. 3) was 256 (149-438) Hyalella equivalents. When SFVs from tests with nominal concentrations were included, the HC5 for 93 arthropod species was 9.2 (5.4-16) Hyalella equivalents and the HC5 for 48 fish species was 174 (120-254) Hyalella equivalents.

SSDs for individual pyrethroids were generated from the combined SSDs and compared with data for each individual AI. Results for arthropods are shown in Fig. 4. Observed AI LC50s for individual species (represented by $\mathrm{X}$ symbols on these figures) are generally consistent with the LC50s estimated using Hyalella equivalents. Because the observed LC50s were included in the dataset used to estimate Hyalella equivalents, the estimates were not independent of the observations; with that caveat, the overall consistency of observed LC50s with those estimated from Hyalella equivalents is a measure of the accuracy of the combined SSDs as applied to individual AIs. Due to the small number of species with acute toxicity data for some AIs, derivation of SSDs from data for those AIs alone would have been impossible, but the combined SSD allows HC5s to be estimated for all AIs and used for risk characterization.

\section{Discussion}

The Hyalella equivalent HC5 values can be used to estimate the HC5 for a given AI (in ng/L) from the H. azteca LC50 (in $\mathrm{ng} / \mathrm{L}$ ) for that $\mathrm{AI}$. For example, for bifenthrin, the observed LC50 for H. azteca is $0.5 \mathrm{ng} / \mathrm{L}$; thus the arthropod HC5 for that AI (based on tests with measured concentrations only) is estimated to be $2.4 \mathrm{ng} / \mathrm{L}$ (i.e., $4.8 \times 0.5$ ) and the fish HC5 is estimated to be $128 \mathrm{ng} / \mathrm{L}$. HC5 values derived for all AIs from the combined SSDs are shown in Table 4. 
Table 1 Geometric mean LC50 values (Hyalella equivalents) for pyrethroids in arthropod species used in SSD analysis

\begin{tabular}{|c|c|c|c|c|c|c|}
\hline \multirow[b]{2}{*}{ Species } & \multicolumn{3}{|c|}{ Measured and nominal } & \multicolumn{3}{|l|}{ Measured only } \\
\hline & Geomean (range) & $\mathrm{N}^{\mathrm{a}}$ & Rank & Geomean (range) & $\mathrm{N}^{\mathrm{a}}$ & Rank \\
\hline Hyalella azteca & $1.0(1.0-1.0)$ & 9 & 1 & $1.0(1.0-1.0)$ & 9 & 1 \\
\hline Menippe mercenaria & $2.6(2.6)$ & 1 & 2 & & & \\
\hline Gammarus lacustris lacustris & $3.6(3.6)$ & 1 & 3 & & & \\
\hline Crangonyx pseudogracilis & $4.6(4.6)$ & 1 & 4 & & & \\
\hline Gammarus pseudolimnaeus & $6.2(6.2)$ & 1 & 5 & $6.2(6.2)$ & 1 & 2 \\
\hline Americamysis bahia & $8.8(4.5-22)$ & 8 & 6 & $8.8(4.5-22)$ & 8 & 3 \\
\hline Chaoborus sp. & $9.3(9.3)$ & 1 & 7 & $9.3(9.3)$ & 1 & 4 \\
\hline Acartia tonsa & $11(11)$ & 1 & 8 & & & \\
\hline Hexagenia bilineata & $14(14)$ & 1 & 9 & $14(14)$ & 1 & 6 \\
\hline Palaemonetes pugio & $21(7.1-34)$ & 5 & 10 & & & \\
\hline Asellus aquaticus & $21(12-87)$ & 4 & 11 & $87(87)$ & 1 & 14 \\
\hline Baetis rhodani & $22(22)$ & 1 & 12 & $22(22)$ & 1 & 7 \\
\hline Cloeon dipterum & $26(4-130)$ & 3 & 13 & $67(36-130)$ & 2 & 13 \\
\hline Procambarus blandingi & $30(30)$ & 1 & 14 & & & \\
\hline Eurytemora affinis & $46(33-65)$ & 2 & 15 & $46(33-65)$ & 2 & 9 \\
\hline Procloeon sp. & $47(13-170)$ & 2 & 16 & & & \\
\hline Penaeus aztecus & $49(49)$ & 1 & 17 & & & \\
\hline Pseudodiaptomus forbesi & $56(56)$ & 1 & 18 & $56(56)$ & 1 & 11 \\
\hline Isoperla quinquepunctata & $57(57)$ & 1 & 19 & $57(57)$ & 1 & 12 \\
\hline Orconectes spp. & $60(30-120)$ & 2 & 20 & $120(120)$ & 1 & 18 \\
\hline Gammarus pulex & $68(16-220)$ & 5 & 21 & $56(16-220)$ & 4 & 10 \\
\hline Penaeus duorarum & $87(31-320)$ & 3 & 22 & $45(31-64)$ & 2 & 8 \\
\hline Piona carnea & $89(89)$ & 1 & 23 & & & \\
\hline Corixa sp. & $100(100)$ & 1 & 24 & $100(100)$ & 1 & 15 \\
\hline Diphetor hageni & $100(100)$ & 1 & 25 & $100(100)$ & 1 & 16 \\
\hline Hyalella curvispina & $100(100)$ & 1 & 26 & & & \\
\hline Agrypnia varia & $110(110)$ & 1 & 27 & & & \\
\hline Aedes vexans & $130(130)$ & 1 & 28 & & & \\
\hline Culex restuans & $130(130)$ & 1 & 29 & & & \\
\hline Procambarus clarkii & $150(61-530)$ & 3 & 30 & $110(110)$ & 1 & 17 \\
\hline Hydracarina & $160(160)$ & 1 & 31 & $160(160)$ & 1 & 20 \\
\hline Chironomus dilutus & $170(27-1100)$ & 5 & 32 & $150(27-1100)$ & 4 & 19 \\
\hline Chironomus riparius & $170(12-2400)$ & 2 & 33 & $12(12)$ & 1 & 5 \\
\hline Chironomus salinarius & $170(10-4200)$ & 3 & 34 & & & \\
\hline Chydorus sp. & $180(180)$ & 1 & 35 & & & \\
\hline Taenionema sp. & $190(190)$ & 1 & 36 & $190(190)$ & 1 & 21 \\
\hline Serratella micheneri & $190(190)$ & 1 & 37 & $190(190)$ & 1 & 23 \\
\hline Goeldichironomus holoprasinus & $200(200)$ & 1 & 38 & & & \\
\hline Temora longicornis & $210(210)$ & 1 & 39 & & & \\
\hline Oithona similis & $250(250)$ & 1 & 40 & & & \\
\hline Paratya australiensis & $250(250)$ & 1 & 41 & & & \\
\hline Aedes stimulans & $280(280)$ & 1 & 42 & & & \\
\hline Palaemon serratus & $280(280)$ & 1 & 43 & & & \\
\hline Diaptomus sp. & $290(290)$ & 1 & 44 & & & \\
\hline Baetis tricaudatus & $290(290)$ & 1 & 45 & $290(290)$ & 1 & 24 \\
\hline Ceriodaphnia dubia & $320(36-1200)$ & 7 & 46 & & & \\
\hline Marilia sp. & $320(320)$ & 1 & 47 & $320(320)$ & 1 & 25 \\
\hline Daphnia magna & $330(56-3300)$ & 9 & 48 & $460(170-3300)$ & 7 & 29 \\
\hline Glyptotendipes paripes & $340(340)$ & 1 & 49 & & & \\
\hline Chaoborus crystallinus & $360(360)$ & 1 & 50 & & & \\
\hline Trichoptera & $360(360)$ & 1 & 51 & $360(360)$ & 1 & 27 \\
\hline Procladius sp. & $390(390)$ & 1 & 52 & & & \\
\hline Aedes trivittatus & $430(430)$ & 1 & 53 & & & \\
\hline Ischnura elegans & $430(430)$ & 1 & 54 & $430(430)$ & 1 & 28 \\
\hline Aedes hendersoni & $500(500)$ & 1 & 55 & & & \\
\hline
\end{tabular}


Table 1 (continued)

\begin{tabular}{|c|c|c|c|c|c|c|}
\hline \multirow[b]{2}{*}{ Species } & \multicolumn{3}{|l|}{ Measured and nominal } & \multicolumn{3}{|l|}{ Measured only } \\
\hline & Geomean (range) & $\mathrm{N}^{\mathrm{a}}$ & Rank & Geomean (range) & $\mathrm{N}^{\mathrm{a}}$ & Rank \\
\hline Uca pugilator & $590(330-1800)$ & 3 & 56 & $350(350)$ & 1 & 26 \\
\hline Tanypus grodhausi & $650(650)$ & 1 & 57 & & & \\
\hline Spicodiaptomus chelospinus & $710(710)$ & 1 & 58 & & & \\
\hline Hydropsyche sp. & $730(190-2500)$ & 3 & 59 & $190(190)$ & 1 & 22 \\
\hline Cricotopus sp. & $760(760)$ & 1 & 60 & & & \\
\hline Hexagenia sp. & $780(780)$ & 1 & 61 & $780(780)$ & 1 & 30 \\
\hline Eretes sticticus & $830(830)$ & 1 & 62 & & & \\
\hline Aedes atropalpus & $880(880)$ & 1 & 63 & & & \\
\hline Fallceon quilleri & $890(890)$ & 1 & 64 & $890(890)$ & 1 & 31 \\
\hline Aedes triseriatus & $950(950)$ & 1 & 65 & & & \\
\hline Cyclops sp. & $1000(1000)$ & 1 & 66 & $1000(1000)$ & 1 & 32 \\
\hline Caenis sp. & $1200(1200)$ & 1 & 67 & & & \\
\hline Culex pipiens & $1300(100-8500)$ & 4 & 68 & & & \\
\hline Helicopsyche sp. & $1300(1300)$ & 1 & 69 & $1300(1300)$ & 1 & 33 \\
\hline Simulium vitattum & $1300(640-2600)$ & 2 & 70 & & & \\
\hline Enellagma sp. & $1300(410-2500)$ & 3 & 71 & & & \\
\hline Culex quinquefasciatus & $1400(93-21,000)$ & 6 & 72 & & & \\
\hline Chironomus decorus & $1400(640-3200)$ & 2 & 73 & & & \\
\hline Aedes aegypti & $1600(46-6500)$ & 5 & 74 & & & \\
\hline Chironomus utahensis & $1700(1700)$ & 1 & 75 & & & \\
\hline Heptageniidae & $1900(630-4600)$ & 3 & 76 & & & \\
\hline Acartia clausi & $2000(2000)$ & 1 & 77 & & & \\
\hline Anopheles stephensi & $2200(2200)$ & 1 & 78 & & & \\
\hline Aedes albopictus & $2400(280-10,000)$ & 3 & 79 & & & \\
\hline Pseudocalanus elongatus & $2400(2400)$ & 1 & 80 & & & \\
\hline Brachycentrus americanus & $2700(2700)$ & 1 & 81 & & & \\
\hline Hesperoperla pacifica & $4700(4700)$ & 1 & 82 & & & \\
\hline Nectopsyche sp. & $4700(4700)$ & 1 & 83 & $4700(4700)$ & 1 & 34 \\
\hline Moina micrura & $5200(5200)$ & 1 & 84 & & & \\
\hline Chironomus thummi & $8900(8900)$ & 1 & 85 & & & \\
\hline Coenagrion puella & $8900(8900)$ & 1 & 86 & & & \\
\hline Corixa punctata & $8900(8900)$ & 1 & 87 & & & \\
\hline Gyrinus natator & $8900(8900)$ & 1 & 88 & & & \\
\hline Notonecta sp. & $8900(8900)$ & 1 & 89 & & & \\
\hline Dicrotendipes californicus & $10,000(10,000)$ & 1 & 90 & & & \\
\hline Hydrophilus sp. & $10,000(6400-15,000)$ & 3 & 91 & & & \\
\hline Ostracoda & $11,000(11,000)$ & 1 & 92 & $11,000(11,000)$ & 1 & 35 \\
\hline Thamnocephalus platyurus & $11,000(11,000)$ & 1 & 93 & $11,000(11,000)$ & 1 & 36 \\
\hline
\end{tabular}

${ }^{a}$ Number of pyrethroid active ingredient LC50s (Hyalella equivalents) included in geometric mean for species

The HC5 values are useful for calculating Risk Quotients (EPA 2004) in screening-level risk assessments of individual AIs. The combined pyrethroid SSDs can also be used to derive full SSDs for a given AI (as shown for arthropods in Fig. 4), which can be integrated with estimated exposure distributions to construct Joint Probability Curves (ECOFRAM 1999) for refined risk characterization of individual AIs.

The HC5 for all animals is the basis for water quality standards in many countries (CCME 2007; Crommentuijn et al. 2000; RIVM 2001; Stephan et al. 1985; Warne et al. 2018). Since many chemicals have been tested with relatively few animal species, some regulatory schemes (e.g.
Stephan et al. 1985) have established specific criteria for inclusion of species from various taxonomic groups to ensure that the resulting water quality standards are broadly protective. In the case of pyrethroids, arthropods are substantially more sensitive than other animal taxa, and pooling all animals would result in a bimodal SSD that represents neither arthropods nor other taxa. The resulting HC5 for all animals would be distorted by the relative numbers of species in each taxon and would not be a reliable indicator of the sensitivity of a natural species assemblage. Given the large difference in sensitivity between arthropods and other taxa, the HC5 for the most sensitive taxon would be a more appropriate basis for water quality criteria. 
Table 2 Geometric mean LC50 values (Hyalella equivalents) for pyrethroids in fish species used in SSD analysis

\begin{tabular}{|c|c|c|c|c|c|c|}
\hline \multirow[b]{2}{*}{ Species } & \multicolumn{3}{|l|}{ Measured and nominal } & \multicolumn{3}{|l|}{ Measured only } \\
\hline & Geomean (range) & $\mathrm{N}^{\mathrm{a}}$ & Rank & Geomean (range) & $\mathrm{N}^{\mathrm{a}}$ & Rank \\
\hline Acipenser brevirostris & $170(170)$ & 1 & 1 & & & \\
\hline Acipenser oxyrhynchus & $170(170)$ & 1 & 2 & & & \\
\hline Oncorhynchus clarki & $180(140-230)$ & 2 & 3 & & & \\
\hline Salmo salar & $210(210)$ & 1 & 4 & & & \\
\hline Hybopsis monacha & $240(240)$ & 1 & 5 & & & \\
\hline Oncorhynchus apache & $240(240)$ & 1 & 6 & & & \\
\hline Leuciscus idus & $260(260)$ & 1 & 7 & $260(260)$ & 1 & 1 \\
\hline Alosa sapidissima & $300(300)$ & 1 & 8 & & & \\
\hline Menidia menidia & $310(310)$ & 1 & 9 & $310(310)$ & 1 & 2 \\
\hline Etheostoma lepidum & $390(390)$ & 1 & 10 & & & \\
\hline Etheostoma fonticola & $480(480)$ & 1 & 11 & & & \\
\hline Notropis mekistocholis & $590(590)$ & 1 & 12 & & & \\
\hline Oncorhynchus mykiss & $620(180-1600)$ & 9 & 13 & $600(180-1600)$ & 8 & 4 \\
\hline Salvelinus fontinalis & $670(670)$ & 1 & 14 & $670(670)$ & 1 & 5 \\
\hline Cnesterodon decemmaculatus & $770(770)$ & 1 & 15 & $770(770)$ & 1 & 6 \\
\hline Mugil cephalus & $790(790)$ & 1 & 16 & $790(790)$ & 1 & 7 \\
\hline Xyrauchen texanus & $850(850)$ & 1 & 17 & & & \\
\hline Gambusia affinis & $870(870)$ & 1 & 18 & $870(870)$ & 1 & 8 \\
\hline Menidia beryllina & $890(890)$ & 1 & 19 & $890(890)$ & 1 & 9 \\
\hline Oreochromis aureus & $910(910)$ & 1 & 20 & $910(910)$ & 1 & 10 \\
\hline Ictalurus punctatus & $1100(380-3600)$ & 4 & 21 & $450(380-530)$ & 2 & 3 \\
\hline Pogonichthys macrolepidotus & $1100(1100)$ & 1 & 22 & & & \\
\hline Melanotaenia duboulayi & $1200(1200)$ & 1 & 23 & & & \\
\hline Lepomis macrochirus & $1200(520-8200)$ & 9 & 24 & $930(520-3200)$ & 7 & 11 \\
\hline Sciaenops ocellatus & $1200(1200)$ & 1 & 25 & & & \\
\hline Gasterosteus aculeatus & $1300(1300)$ & 1 & 26 & $1300(1300)$ & 1 & 12 \\
\hline $\begin{array}{l}\text { Poeciliopsis occidentalis } \\
\text { occidentalis }\end{array}$ & $1400(1400)$ & 1 & 27 & & & \\
\hline Scaphirhynchus platorynchus & $1400(1400)$ & 1 & 28 & & & \\
\hline Danio rerio & $2000(360-3100)$ & 4 & 29 & $2600(2100-3100)$ & 2 & 16 \\
\hline Pimephales promelas & $2000(830-4000)$ & 8 & 30 & $2100(830-4000)$ & 7 & 13 \\
\hline Salmo trutta & $2100(2100)$ & 1 & 31 & $2100(2100)$ & 1 & 14 \\
\hline Oncorhynchus kisutch & $2400(2400)$ & 1 & 32 & & & \\
\hline Morone saxatilis & $2600(2600)$ & 1 & 33 & $2600(2600)$ & 1 & 15 \\
\hline Cyprinodon bovinus & $3000(3000)$ & 1 & 34 & & & \\
\hline Fundulus heteroclitus & $3300(3300)$ & 1 & 35 & & & \\
\hline Ptychocheilus lucius & $3500(3500)$ & 1 & 36 & & & \\
\hline Gila elegans & $3600(3600)$ & 1 & 37 & & & \\
\hline Atherinops affinis & $3600(3600)$ & 1 & 38 & & & \\
\hline Pollimyrus isidori & $3700(3700)$ & 1 & 39 & & & \\
\hline Pseudaphritis urvillii & $3900(3900)$ & 1 & 40 & $3900(3900)$ & 1 & 19 \\
\hline Cyprinodon variegatus & $3900(1100-36,000)$ & 7 & 41 & $4500(1100-36,000)$ & 5 & 22 \\
\hline Galaxias maculatus & $4200(4200)$ & 1 & 42 & $4200(4200)$ & 1 & 21 \\
\hline Cyprinus carpio & $5000(2100-12,000)$ & 4 & 43 & $3700(2100-10,000)$ & 3 & 17 \\
\hline Oryzias latipes & $7400(1600-55,000)$ & 3 & 44 & $4700(4700)$ & 1 & 23 \\
\hline Labeo rohita & $9400(9400)$ & 1 & 45 & & & \\
\hline
\end{tabular}


Table 2 (continued)

\begin{tabular}{|c|c|c|c|c|c|c|}
\hline \multirow[b]{2}{*}{ Species } & \multicolumn{3}{|l|}{ Measured and nominal } & \multicolumn{3}{|l|}{ Measured only } \\
\hline & Geomean (range) & $\mathrm{N}^{\mathrm{a}}$ & Rank & Geomean (range) & $\mathrm{N}^{\mathrm{a}}$ & Rank \\
\hline Poecilia reticulata & $11,000(2000-35,000)$ & 4 & 46 & $3900(2000-7700)$ & 2 & 18 \\
\hline Oreochromis niloticus & $16,000(3900-38,000)$ & 3 & 47 & $3900(3900)$ & 1 & 20 \\
\hline Carassius auratus & $30,000(30,000)$ & 1 & 48 & $30,000(30,000)$ & 1 & 24 \\
\hline
\end{tabular}

${ }^{a}$ Number of pyrethroid active ingredient LC50s (Hyalella equivalents) included in geometric mean for species

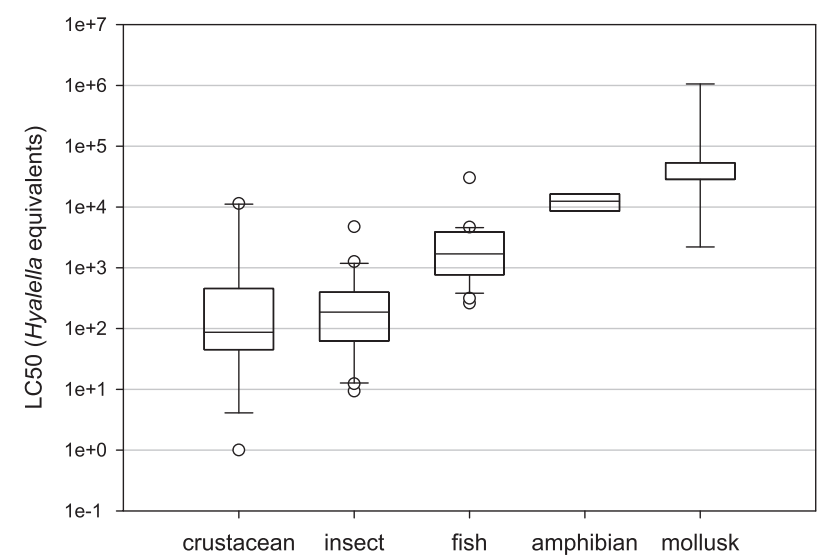

Fig. 1 The relative sensitivity (Hyalella equivalent LC50s) of crustaceans, insects, fish, amphibians, and mollusks to pyrethroids, using data from tests with measured concentrations. Horizontal lines in boxes indicate twenty fifth, fiftieth (median), and seventy fifth percentiles; vertical bars indicate tenth and ninetieth percentiles (where data were sufficient to calculate); individual points are values above the ninetieth percentile or below the tenth percentile

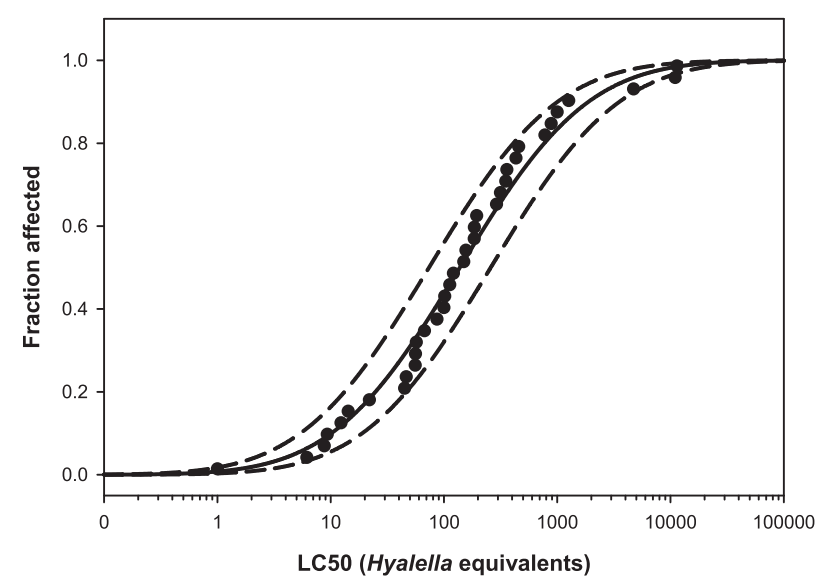

Fig. 2 Species sensitivity distributions for arthropods based on Hyalella azteca equivalents for all pyrethroids, using data from tests with measured concentrations. Circles represent Hyalella azteca equivalents for individual species. Solid line is model-fitted distribution; dashed lines indicate $95 \%$ prediction interval

The combined SSDs offer significant benefits for risk assessment of pyrethroids. Because the combined SSDs include data for 36 arthropod species (93 species if nominal

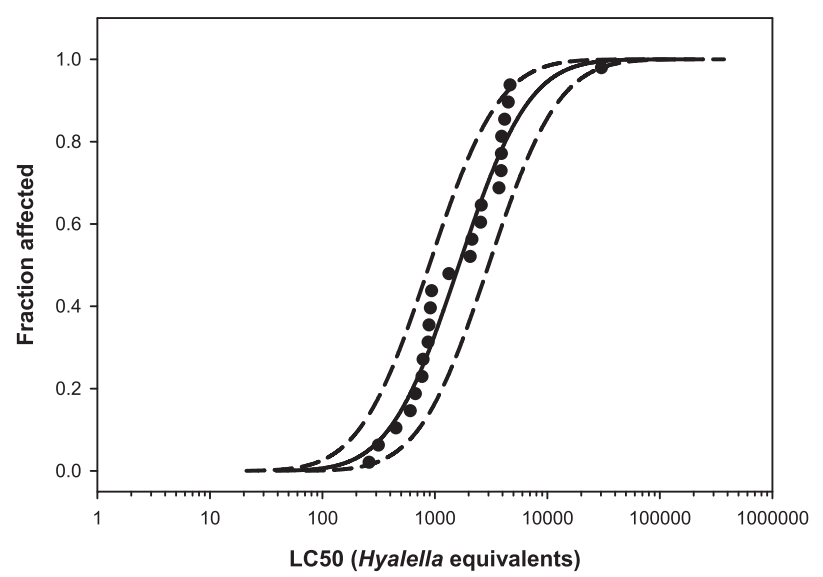

Fig. 3 Species sensitivity distributions for fish based on Hyalella equivalents for all pyrethroids, using data from tests with measured concentrations. Circles represent Hyalella equivalents for individual species. Solid line is model-fitted distribution; dashed lines indicate $95 \%$ prediction interval

Table 3 Results of lognormal regression analysis of combined pyrethroid SSDs based on Hyalella equivalents

\begin{tabular}{lccccc}
\hline Taxon & $\mathrm{N}^{\mathrm{a}}$ & Intercept & Slope & $\mathrm{R}^{2}$ & HC5 (95\% prediction interval) \\
\hline Tests with measured exposure concentrations \\
Arthropods & 36 & 2.585 & 1.128 & 0.978 & $4.8(2.8-8.3)$ \\
Fish & 24 & -1.558 & 2.040 & 0.936 & $256(149-438)$ \\
Tests with measured and nominal exposure concentrations \\
Arthropods \\
93 & 2.326 & 1.070 & 0.978 & $9.2(5.4-16)$ \\
Fish & 48 & -0.781 & 1.844 & 0.972 & $174(120-254)$ \\
\hline
\end{tabular}

${ }^{\mathrm{a}}$ Number of species in SSD

${ }^{\mathrm{b}}$ Hyalella equivalents

tests are included) and 24 fish species (48 species if nominal tests are included), they provide a much broader taxonomic representation than SSDs using data for single AIs alone. Moreover, the large numbers of species included in the combined SSDs confer greater statistical precision in HC5 estimation. The combined SSDs also enable a broadly representive, statistically rigorous analysis of AIs such as cyfluthrin, esfenvalerate, and fenpropathrin for which relatively few toxicity data are available.

The combined pyrethroid SSDs are subject to a number of uncertainties. A large fraction of the Hyalella equivalents 

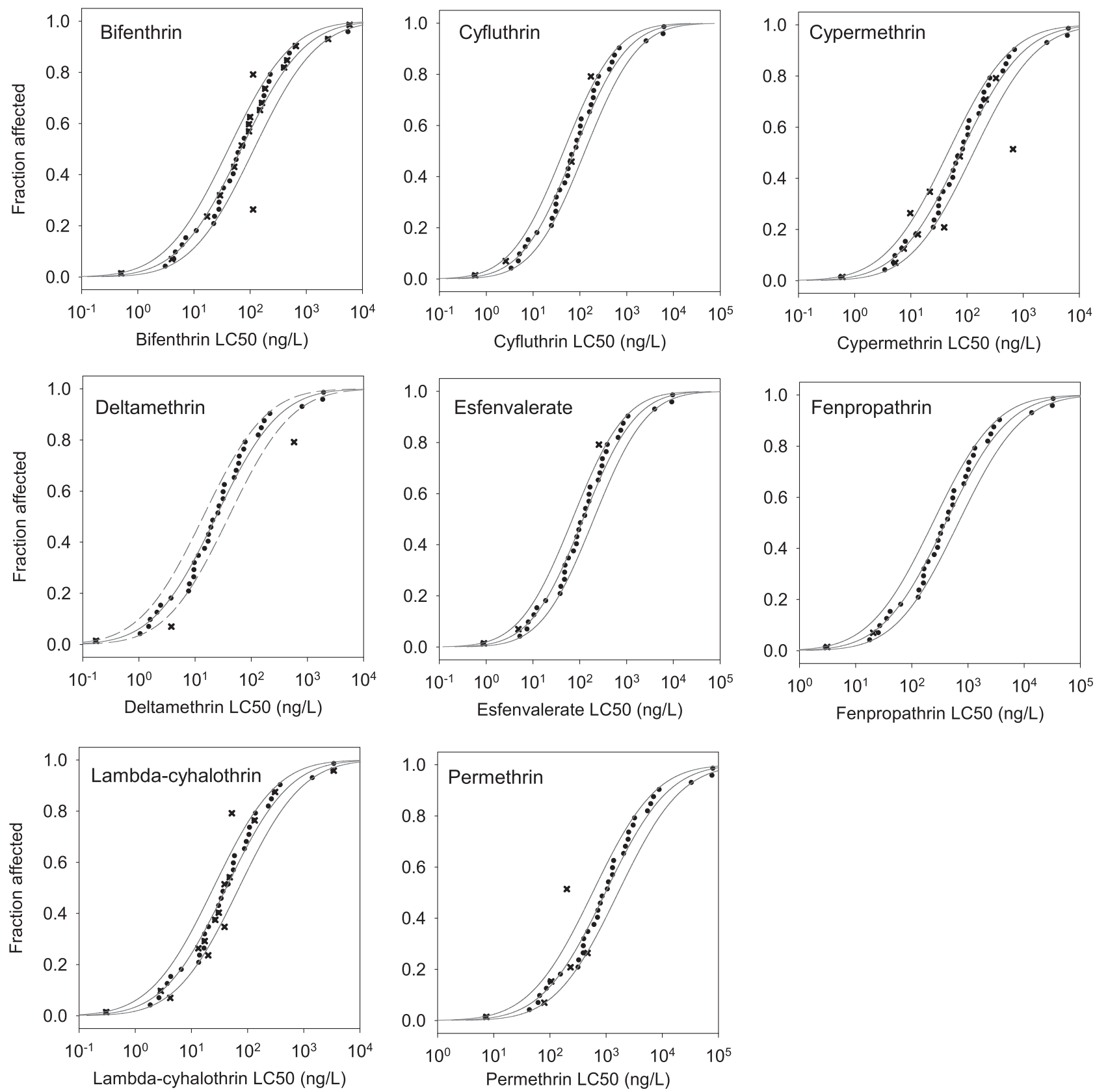

Fig. 4 SSDs for arthropods for individual pyrethroids derived using the combined SSD approach based on Hyalella equivalents. Circles represent estimated LC50s for individual species; X symbols represent observed LC50s plotted next to the estimated LC50s for the same

species. Solid lines are model-fitted distributions; dashed lines indicate 95\% prediction intervals. Only data from studies with measured exposure concentrations were included in this analysis

for both arthropods and fish are based on only a single AI, and for some of the species with more extensive data, Hyalella equivalents vary considerably across AIs (see Table S3-1). Some of the LC50 values for insensitive species exceed the reported water solubility of the tested pyrethroids (though the underlying data for all individual studies were examined and data were not used if concentration-response relationships were irregular, as would have been the case if test solutions contained insoluble pyrethroid). Finally, estimation of pyrethroid toxicity to fish and other non-arthropods could be affected by differences in uptake and metabolism between those species and $H$. azteca.

The similarity of toxicity profiles across AIs and the existence of a highly consistent dataset for $H$. azteca makes this approach especially useful for pyrethroids, but 
Table 4 HC5 values (with $95 \%$ prediction intervals) for individual pyrethroids based on HC5 from combined SSD

\begin{tabular}{lccccc}
\hline & \multicolumn{2}{l}{ Measured concentrations $(\mathrm{ng} / \mathrm{L})$} & & \multicolumn{2}{l}{ Measured and nominal concentrations (ng/L) } \\
\cline { 2 - 3 } Pyrethroid & Arthropods & Fish & & Arthropods & Fish \\
\hline Bifenthrin & $2.4(1.4-4.2)$ & $128(75-219)$ & & $4.6(2.7-8.0)$ & $87(60-127)$ \\
Cyfluthrin & $2.6(1.5-4.6)$ & $140(82-241)$ & & $5.1(3.0-8.8)$ & $96(66-140)$ \\
$\lambda$-cyhalothrin & $1.4(0.84-2.5)$ & $77(45-131)$ & & $2.8(1.6-4.8)$ & $52(36-76)$ \\
Cypermethrin & $2.7(1.6-4.6)$ & $140(83-245)$ & & $5.2(3.0-9.0)$ & $97(67-142)$ \\
Deltamethrin & $0.82(0.47-1.4)$ & $44(25-74)$ & & $1.6(0.92-2.7)$ & $30(20-43)$ \\
Esfenvalerate & $4.1(2.4-7.0)$ & $218(127-372)$ & & $7.8(4.6-14)$ & $148(102-216)$ \\
Fenpropathrin & $14(8.1-24)$ & $742(432-1270)$ & & $27(16-46)$ & $505(348-737)$ \\
Permethrin & $34(20-58)$ & $1792(1040-3066)$ & $64(38-112)$ & $1218(840-1778)$ \\
\hline
\end{tabular}

a similar approach could be applied to other classes of pesticides.

\section{Conclusions}

The extensive aquatic toxicity database for 9 pyrethroids provides the basis for a combined pyrethroid SSD based on Hyalella equivalents. The resulting SSDs, incorporating acute toxicity data for large numbers of arthropod and fish species, can be used to estimate the HC5 for a given AI from the observed $H$. azteca LC50 for that AI. The combined SSDs are more taxonomically representative and statistically precise than SSDs based on the more limited datasets for individual pyrethroid AIs. HC5 values calculated for individual AIs based on the combined SSDs are useful for risk assessment and could be used in derivation of water quality criteria.

Acknowledgements The work of Compliance Services International was conducted under contract with the Pyrethroid Working Group, whose members include AMVAC Chemical Corporation, BASF Corporation, Bayer CropScience LP, FMC Corporation, Syngenta Crop Protection, Inc., and Valent USA.

\section{Compliance with ethical standards}

Conflict of interest The authors declare that they have no conflict of interest.

Publisher's note: Springer Nature remains neutral with regard to jurisdictional claims in published maps and institutional affiliations.

Open Access This article is distributed under the terms of the Creative Commons Attribution 4.0 International License (http://crea tivecommons.org/licenses/by/4.0/), which permits use, duplication, adaptation, distribution, and reproduction in any medium or format, as long as you give appropriate credit to the original author(s) and the source, provide a link to the Creative Commons license, and indicate if changes were made.

\section{References}

CCME (2007) A protocol for the derivation of water quality guidelines for the protection of aquatic life. Canadian Council of Ministers of the Environment, Winnipeg

Crommentuijn T, Sijm D, de Bruin J, van Leeuwen K, van de Plassche E (2000) Maximum permissible and negligible concentrations for some organic substances and pesticides. J Environ Manag 58:297-312

ECOFRAM (1999) Aquatic draft report. Ecological Committee on FIFRA Risk Assessment Methods (ECOFRAM). U.S. Environmental Protection Agency, Washington, DC

EPA (2004) The Office of Pesticide Programs ecological assessment process: Addressing potential impacts on listed species and critical habitat. U.S. Environmental Protection Agency, Alexandria

EPA (2016) Preliminary comparative environmental fate and ecological risk assessment for the registration review of eight synthetic pyrethroids and the pyrethrins. U.S. Environmental Protection Agency, Washington, DC

Maltby L, Blake N, Brock T, Van den Brink P (2005) Insecticide species sensitivity distributions: Importance of test species selection and relevance to aquatic ecosystems. Environ Toxicol Chem 24:379-388

Neter J, Wasserman W, Kutner M (1990) Applied Linear Statistical Models, 3rd edn. Irwin, Boston

Posthuma L, Traas T, Suter G (eds) (2002) Species sensitivity distributions in risk assessment. CRC Press, Boca Raton

RIVM (2001) Guidance document on deriving environmental risk limits in the Netherlands. National Institute of Public Health and the Environment, Bilthoven

Stephan C, Mount D, Hansen D, Gentile J, Chapman G, Brungs W (1985) Guidelines for deriving numerical national water quality criteria for the protection of aquatic organisms and their uses. $U$. S. Environmental Protection Agency, Washington, DC

Van den Brink P, Blake N, Brock T, Maltby L (2006) Predictive value of species sensitivity distributions for effects of herbicides in freshwater ecosystems. Hum Ecol Risk Assess 12:645-674

Warne M, Batley G, van Dam R, Chapman J, Fox D, Hickey C, Stauber J (2018) Revised method for deriving Australian and New Zealand water quality guideline values for toxicantsupdate of 2015 version. Australian Government Department of Agriculture and Water Resources, Canberra 